\title{
Renal Function in Preterm Neonates
}

\author{
A. BUEVA AND J.-P. GUIGNARD \\ Service de Pédiatrie, Centre Hospitalier Universitaire Vaudois, 1001 Lausanne, Switzerland
}

\section{ABSTRACT}

The plasma creatinine concentration is elevated at birth and decreases concomitantly with the rapid increase in glomerular filtration rate that occurs in the first postnatal weeks. The velocity of these changes was assessed during the first $3 \mathrm{wk}$ of life of 66 term and preterm infants. The plasma creatinine concentration, creatinine clearance, and sodium fractional excretion were measured serially at weekly intervals, starting $1-4 \mathrm{~d}$ after birth [mean $=1.5 \pm$ 0.8 (SD) d]. Premature infants were separated into three groups according to their birth weight: group 1, 1001 to $1500 \mathrm{~g}$; group 2, 1501 to $2000 \mathrm{~g}$; and group 3, 2001 to 2500 g. Group 4 included 28 term infants (mean birth weight $=$ $3165 \pm 78 \mathrm{~g}$ ). Mean gestational ages in the preterm groups were $31.3,32.8$, and 34.4 wk in groups 1,2 , and 3 , respectively. The plasma creatinine concentration on $\mathrm{d} 1.5$ was significantly higher in preterm $(91 \pm 4 \mu \mathrm{mol} / \mathrm{L})$ compared with term infants $(66 \pm 3 \mu \mathrm{mol} / \mathrm{L})$. The differences in plasma creatinine were still present during the second week of life, with values of $64 \pm 5,58 \pm 7,47 \pm 8$, and $40 \pm 4$ $\mu \mathrm{mol} / \mathrm{L}$ in groups $1,2,3$, and 4 , respectively. The difference vanished by $\mathrm{d} 22-23$. On d 1.5 , creatinine clearance correlated positively with gestational age, amounting to $0.65 \pm 0.14,0.92 \pm 0.19,1.42 \pm 0.31$, and $3.36 \pm 0.32$ $\mathrm{mL} / \mathrm{min}$ in groups $1,2,3$, and 4 , respectively. Creatinine clearance increased rapidly with postnatal age, the velocity of the maturation being less marked in the most premature infants. The fractional excretion of sodium was significantly higher in the most premature infants, with values of $2.0 \pm 0.3,2.2 \pm 0.5,1.1 \pm 0.2$, and $0.3 \pm 0.1 \%$ in groups 1 , 2,3 , and 4 , respectively. The differences vanished by the third week of life. The negative correlation between plasma creatinine on d 1.5 and gestational age suggests that the neonate's creatinine plasma concentration does not simply reflect the mother's plasma concentration. (Pediatr Res 36: 572-577, 1994)
GFR, glomerular filtration rate
BW, birth weight
VLBW, very low birth weight
GA, gestational age

Abbreviations
Renal function is low at birth, especially in the most premature infants (1-5). The functional maturation of the GFR after birth has been well documented in term neonates. Studies using inulin $(3,4,6,7)$ or creatinine $(1,2$, $8-12)$ as a glomerular marker have demonstrated a rapid increase in GFR in the neonatal period, with the value of inulin clearance actually doubling in the first $2 \mathrm{wk}$ of life $(3,4)$.

The pattern of maturation of GFR in premature neonates has been the subject of controversy. Studies using inulin, the gold standard for measuring GFR, have shown a characteristic pattern in the development of GFR during gestation. From the 28th to the 35 th wk of gestation, GFR (expressed in $\mathrm{mL} / \mathrm{min} / 1.73 \mathrm{~m}^{2}$ ) increases rapidly (4). Because kidney size bears a linear relationship to the body surface area (13), this finding indicates that renal

Received October 25, 1993; accepted May 15, 1994

Correspondence and reprint requests: J.-P. Guignard, M.D., Service de Pédiatrie, CHUV, 1011 Lausanne, Switzerland.

Supported in part by Grants 3-808-0.86, 32-26395.89, and 32-36574.92 of the Swiss National Science Foundation and a research grant from the Nestlé Foundation (A.B.). function matures more rapidly than renal mass. Thereafter, GFR reaches a plateau until the end of gestation, indicating that renal function and renal mass mature in parallel $(4,14)$. As in term neonates, birth is followed by a rapid increase in inulin clearance during the first weeks of life $(3,4)$. The velocity of the postnatal increase in inulin clearance is slightly inferior in premature neonates compared with term neonates, but the difference does not appear to be statistically significant $(1,4,14)$.

Observations based on creatinine clearances in low-BW infants have produced conflicting results $(2,9)$. It has been suggested that creatinine clearance develops very slowly before $34 \mathrm{wk}$ of conceptional age, even though body size and kidney weight increase appreciably during this time. In Arant's study (2), only 34 wk after conception did creatinine clearance appear to increase rapidly, regardless of postnatal age. Thus, in an infant born prematurely at $28 \mathrm{wk}$ of gestation, GFR would not increase rapidly until the infant is $5-6$ wk old (2). The reason for the discrepancy in results obtained from inulin or creatinine clearance studies is not clear. It could be due to the physiologic specifics of creatinine handling in 
premature neonates or to differences in the clearance study protocols $(8,11)$.

Conflicting results have also been published concerning the tubular transport of sodium in premature neonates. Extremely elevated sodium fractional excretion rates have been reported in some studies (15), leading to the conclusion that premature babies present with salt wasting (16). Other authors observed much lower sodium fractional excretion rates, reaching the conclusion that VLBW infants were able to maintain sodium balance during the first week of life $(10,17,18)$. Differences in fluid and electrolyte intakes used in the different study protocols could explain the apparently conflicting results.

The present study was planned with the aim of observing the maturation of creatinine clearance and sodium excretion in the first weeks of life of neonates with various $\mathrm{GA}$ and $\mathrm{BW}$.

\section{METHODS}

Sixty-six physiologically stable newborn infants with GA of 29 to $40 \mathrm{wk}$ and BW of 1009 to $3910 \mathrm{~g}$ were studied during the first $3 \mathrm{wk}$ of life. The clinical diagnosis included prematurity, high risk for infection, transient hyperbilirubinemia, and transient mild respiratory distress syndrome. The estimate of GA was made from the menstrual history and the Dubowitz score (19). The 66 infants were divided into four groups, according to their $\mathrm{BW}$ : group 1, 11 neonates with BW of 1009 to $1500 \mathrm{~g}$ (mean $\mathrm{BW}=1332 \pm 44 \mathrm{~g}$; mean $\mathrm{GA}=31.3 \pm 0.5 \mathrm{wk})$; group 2, 15 neonates with BW of 1520 to $2000 \mathrm{~g}$ (mean BW $=1730$ $\pm 45 \mathrm{~g}$; mean $\mathrm{GA}=32.8 \pm 0.4 \mathrm{wk})$; group 3,12 neonates with $\mathrm{BW}$ of 2040 to $2420 \mathrm{~g}$ (mean $\mathrm{BW}=2239 \pm 41 \mathrm{~g}$; mean GA $34.5 \pm 0.2 \mathrm{wk}$ ); and group 4, 28 term infants with BW of 2400 to $3910 \mathrm{~g}$ (mean BW $=3165 \pm 78 \mathrm{~g}$ ).

All infants were fed a cow-milk formula (Nan or Alprem, Nestlé, Switzerland). Feeding was initiated after $12 \mathrm{~h}$ of life and progressively increased up to the fifth day. The formula supplied $544 \mathrm{~kJ} / \mathrm{kg} / \mathrm{d}(130 \mathrm{kcal} / \mathrm{kg} / \mathrm{d})$ to premature and small-for-gestational-age infants and $418 \mathrm{~kJ} /$ $\mathrm{kg} / \mathrm{d}(100 \mathrm{kcal} / \mathrm{kg} / \mathrm{d})$ to full-term infants. As a rule, fluid intake was $80 \mathrm{~mL} / \mathrm{kg}$ on the first day and then increased by $20 \mathrm{~mL} / \mathrm{kg} / \mathrm{d}$ to reach $150 \mathrm{~mL} / \mathrm{kg} / \mathrm{d}$. Fluid intake was increased by $20 \mathrm{~mL} / \mathrm{kg} / \mathrm{d}$ whenever a decrease in $\mathrm{BW}$ of more than $10 \%$ was observed. It was decreased by 20 $\mathrm{mL} / \mathrm{kg} / \mathrm{d}$ whenever the actual weight exceeded BW during the first $4 \mathrm{~d}$ of life. The cow-milk formula provided 1-1.2 mmol of sodium per $100 \mathrm{~mL}$ of milk (Alprem) or 0.8 mmol of sodium per $100 \mathrm{~mL}$ of milk (Nan). Usual therapeutic measures were continued unchanged throughout the clearance studies.

The infants were studied at weekly intervals on three occasions during daytime. The first blood sample and urine collection were obtained on $\mathrm{d} 1$ in 50 infants, on $d$ 2 in seven, on d 3 in seven, and on d 4 in two infants [mean age $=1.5 \pm 0.8(\mathrm{SD}) \mathrm{d}$ ]. They were thereafter studied on d 8-9, 15-16, and 22-23. Urine was collected by means of an external collecting device. At the end of the 8 - to $12-\mathrm{h}$ collection period, manual suprapubic pressure was applied after the last voiding to ensure complete emptying of the bladder. Urine specimens were stored at $4^{\circ} \mathrm{C}$ before creatinine and sodium analysis. Plasma creatinine concentrations were determined during the urine collection period using $50 \mu \mathrm{L}$ of blood collected from heel prick, which was performed only when needed for other reasons.

Blood pressure was measured in all neonates on three occasions during the urine collection period with the automatic oscillometer method (Dinamap, model 847 XT, Critikon, Inc., Irvine, CA). A 4-cm cuff was used and applied to the left or right upper arm with the baby lying supine. The protocol was approved by an ad hoc ethical committee of the department.

Creatinine in blood and urine was determined by the Jaffé kinetic method, which is available on the Beckman Creatinine Analyzer-II (Beckman Instruments Inc., Fullerton, CA). The endogenous creatinine clearance was taken as an estimate of GFR and calculated from the standard $\mathrm{U} \cdot \mathrm{V} / \mathrm{P}$ formula, where $\mathrm{V}=$ urine flow rate, $\mathrm{U}=$ urine creatinine concentration, and $\mathrm{P}=$ plasma creatinine concentration. It was expressed in $\mathrm{mL} / \mathrm{min}$ or $\mathrm{mL} /$ $\min / 1.73 \mathrm{~m}^{2}$. The body surface area was estimated from the $\mathrm{Du}$ Bois and Du Bois formula (20). Sodium was measured in plasma and urine by flame photometry (Flame Photometer, Il-543, Instrumentation Laboratory, Lexington, MA). The fractional excretion of sodium was assessed by using the standard ratio U/P Na:U/P creatinine, where $U$ and $P$ are the urine and plasma concentrations, respectively, of sodium or creatinine. The fractional excretion of sodium is expressed as a percentage.

Calculations of regression lines and correlation coefficients followed standard statistical methods (21). Mean values are expressed as mean \pm SEM.

\section{RESULTS}

Plasma creatinine concentration. The plasma concentration of creatinine was elevated on the first measurement in all neonates (Fig. 1); the concentration was significantly more elevated $(p<0.001)$ in the low BW infants, with values of $66 \pm 3 \mu \mathrm{mol} / \mathrm{L}$ in the term infants (group 4) compared with $95 \pm 5,90 \pm 5$, and $83 \pm 5 \mu \mathrm{mol} / \mathrm{L}$ in groups 1,2 , and 3 , respectively (Table 1 ). The difference between values observed in term infants $(66 \pm 3 \mu \mathrm{mol} / \mathrm{L})$ and mean values observed in groups 1,2 , and $3(91 \pm 4$ $\mu \mathrm{mol} / \mathrm{L})$ were statistically different $(p<0.001)$. The concentration decreased in all groups during the subsequent $3 \mathrm{wk}$ to reach $27 \pm 7 \mu \mathrm{mol} / \mathrm{L}$ in the term infants and $35 \pm 3,30 \pm 2$, and $30 \pm 10 \mu \mathrm{mol} / \mathrm{L}$ in groups 1,2 , and 3 , respectively. Creatinine plasma concentration did not differ significantly between the four groups on the last measurement, with a mean value of $31 \pm 5 \mu \mathrm{mol} / \mathrm{L}$. Plasma creatinine correlated significantly with postnatal age in all groups $(r=-0.738$ to $-0.795 ; p<0.001)$.

Plasma sodium concentration. The plasma sodium concentration at birth was similar in all groups, with values 


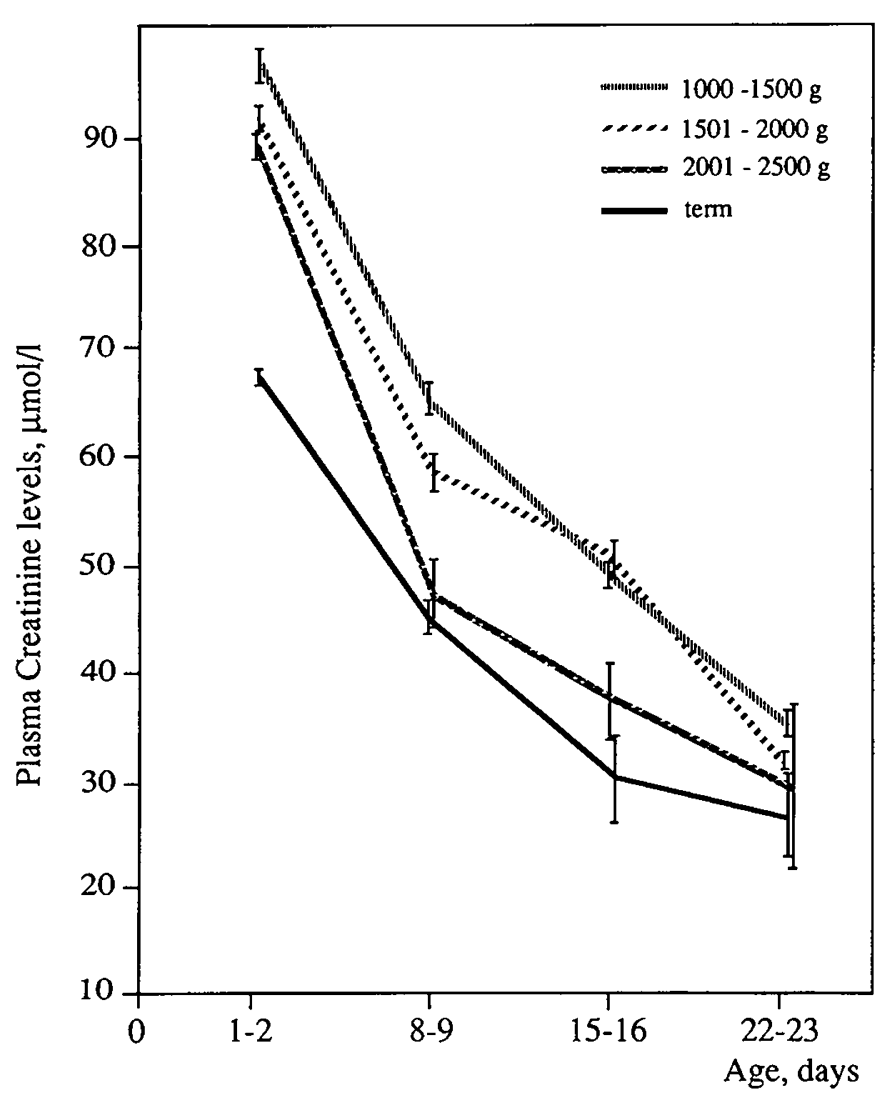

Figure 1. Plasma creatinine concentrations ( $\mu \mathrm{mol} / \mathrm{L}$ ) during the first weeks of life.

ranging from $134 \pm 2$ to $137 \pm 1 \mathrm{mmol} / \mathrm{L}$ (Table 1 ). Except for in infants in group 1, the plasma concentration did not change significantly throughout the observation period. In group 1, the plasma sodium concentration was transiently depressed after 2 wk of life; a nadir of $132 \pm$ $2 \mathrm{mmol} / \mathrm{L}(p<0.05)$ was recorded on $\mathrm{d} 15-16$.

Creatinine clearance. Clearance values were low during the first week of life; the lowest values were observed in

Table 1. Plasma creatinine and sodium concentrations during the first weeks of life*

\begin{tabular}{|c|c|c|c|c|}
\hline \multirow[b]{2}{*}{ Group } & \multicolumn{4}{|c|}{ Postnatal days } \\
\hline & $1-2$ & $8-9$ & $15-16$ & $22-23$ \\
\hline \multicolumn{5}{|l|}{$\mathrm{I}(1001-1500 \mathrm{~g})$} \\
\hline Creatinine $(\mu \mathrm{mol} / \mathrm{L})$ & $95 \pm 5$ & $64 \pm 5$ & $49 \pm 4$ & $35 \pm 3$ \\
\hline Sodium (mmol/L) & $137 \pm 1$ & $135 \pm 1$ & $132 \pm 2 \dagger$ & $136 \pm 2$ \\
\hline$n$ & 11 & 10 & 8 & 8 \\
\hline \multicolumn{5}{|l|}{ II $(1501-2000 \mathrm{~g})$} \\
\hline Creatinine $(\mu \mathrm{mol} / \mathrm{L})$ & $90 \pm 5$ & $58 \pm 7$ & $50 \pm 8$ & $30 \pm 2$ \\
\hline Sodium $(\mathrm{mmol} / \mathrm{L})$ & $136 \pm 2$ & $139 \pm 1$ & $139 \pm 2$ & $139 \pm 1$ \\
\hline$n$ & 15 & 11 & 11 & 9 \\
\hline \multicolumn{5}{|l|}{ III $(2001-2500 \mathrm{~g})$} \\
\hline Creatinine $(\mu \mathrm{mol} / \mathrm{L})$ & $83 \pm 5$ & $47 \pm 8$ & $38 \pm 8$ & $30 \pm 10$ \\
\hline Sodium $(\mathrm{mmol} / \mathrm{L})$ & $134 \pm 2$ & $138 \pm 1$ & $135 \pm 2$ & $136 \pm 3$ \\
\hline$n$ & 12 & 7 & 4 & 2 \\
\hline \multicolumn{5}{|l|}{ IV (full-term) } \\
\hline Creatinine $(\mu \mathrm{mol} / \mathrm{L})$ & $66 \pm 3$ & $40 \pm 4$ & $30 \pm 8$ & $27 \pm 7$ \\
\hline Sodium $(\mathrm{mmol} / \mathrm{L})$ & $136 \pm 1$ & $139 \pm 1$ & $137 \pm 1$ & $135 \pm 3$ \\
\hline$n$ & 28 & 14 & 4 & 3 \\
\hline
\end{tabular}

* Mean values $\pm \mathrm{SEM}$.

$\dagger p<0.05$ compared with values on $\mathrm{d} 1-2$.
Table 2. Creatinine clearance $(\mathrm{mL} / \mathrm{min})$ during the first weeks

\begin{tabular}{cccc}
\hline \multicolumn{4}{c}{ of life* } \\
\cline { 2 - 4 } Group & $1-2$ & $8-9$ & $15-16$ \\
\hline I (1001-1500 g) & $0.65 \pm 0.14$ & $1.31 \pm 0.24$ & $1.73 \pm 0.29$ \\
& $n=11$ & $n=10$ & $n=8$ \\
II (1501-2000 g) & $0.92 \pm 0.19$ & $1.91 \pm 0.24$ & $2.86 \pm 0.56$ \\
& $n=15$ & $n=11$ & $n=11$ \\
III (2001-2500 g) & $1.42 \pm 0.31$ & $3.1 \pm 0.6$ & $3.84 \pm 1.3$ \\
& $n=12$ & $n=7$ & $n=4$ \\
IV (full-term) & $3.36 \pm 0.32$ & $5.17 \pm 0.93$ & $7.52 \pm 1.9$ \\
& $n=28$ & $n=14$ & $n=4$ \\
\hline
\end{tabular}

* Mean values \pm SEM.

infants with the lowest BW. This statement was true both for absolute values of creatinine clearance and for values expressed in relation to the body surface area (Table 2, Fig. 2). Creatinine clearance increased in the following weeks in all infants. This increase correlated significantly with postnatal age. The velocity of the postnatal maturation of creatinine clearance was higher in term neonates $(p<0.01)$ both when creatinine clearance was expressed in absolute terms and when it was factored by the body surface area.

Fractional excretion of sodium. On d 1-2, the fractional excretion of sodium was $0.3 \pm 0.1 \%$ in term infants (Fig. 3 ) and $2.0 \pm 3,2.2 \pm 0.5$, and $1.1 \pm 0.2 \%$ in groups 1,2 , and 3, respectively. The difference between term neonates and the other three groups was statistically significant $(p<0.001)$. All values decreased during the subsequent weeks and were below $0.8 \%$ on d 15-16 (Fig. 3).

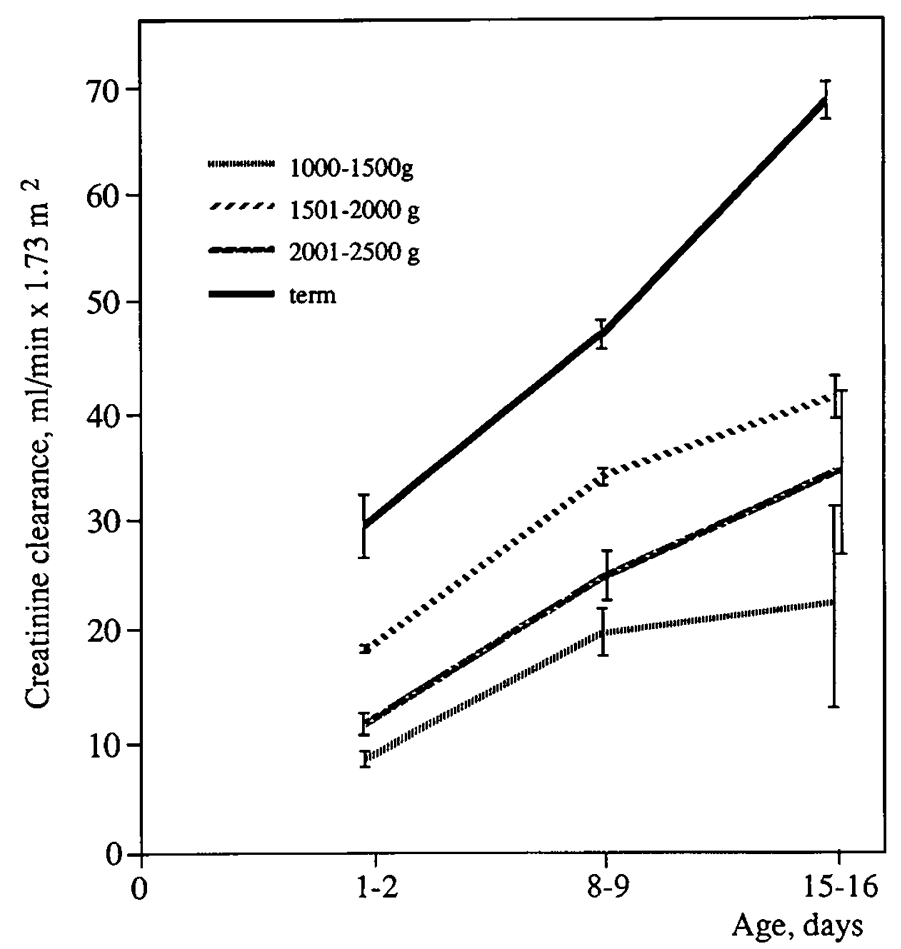

Figure 2. Creatinine clearance $\left(\mathrm{mL} / \mathrm{min} / 1.73 \mathrm{~m}^{2}\right)$ during the first weeks of life. 


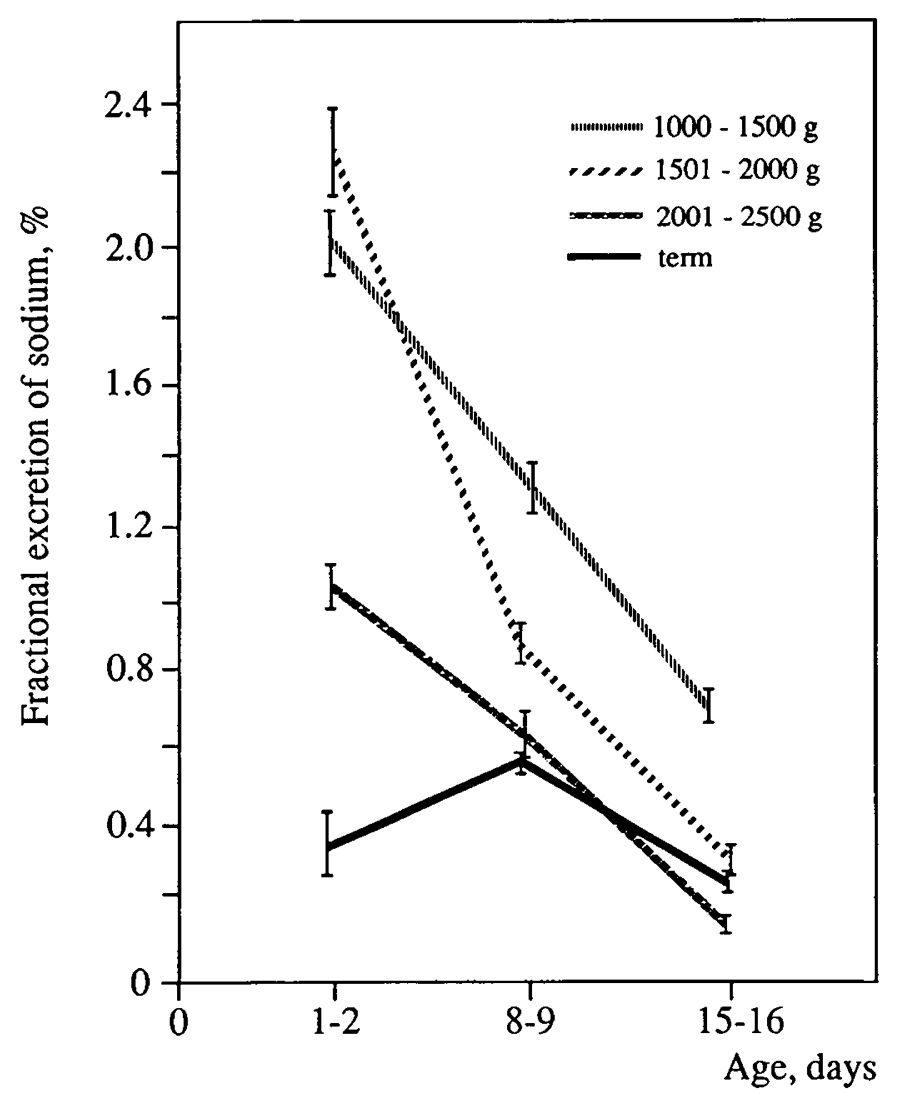

Figure 3. Fractional excretion of sodium during the first weeks of life.

None of the infants developed significant hyponatremia during the study period.

Blood pressure. Blood pressure measured during the urine collection period was lowest in the most premature infants. Mean blood pressure increased linearly with postnatal age $(r=0.92, p<0.001)$ (Table 3). Creatinine clearance correlated significantly with mean blood pressure $(p<0.001)$.

\section{DISCUSSION}

The maturation of both creatinine clearance and sodium tubular transport was followed in 66 newborn babies hospitalized in the neonatal unit. None of these neonates was truly normal, but all were physiologically stable when they were included in the study. Many had conditions that could have transiently impaired GFR, e.g. respiratory distress syndrome (22), artificial ventilation, or the administration of aminoglucosides. Although all these conditions have been shown to possibly impair GFR, they have been observed to do so in severe conditions. Normal renal function has indeed been demonstrated in neonates with compensated respiratory distress syndrome (23). Depression of GFR by artificial positive pressure ventilation has been observed, usually in infants whose intravascular volume was depleted, a situation that was certainly not present in our neonates. Finally, the nephrotoxicity of gentamicin has been diffcult to demonstrate in neonates, especially in the most premature ones. For all these reasons, the factors mentioned above are unlikely to have impaired GFR in our groups of newborn infants. The data collected thus appear clinically relevant.

Plasma creatinine. Our data confirm results observed previously $(8,24)$ demonstrating that 1$)$ the plasma creatinine of newborn infants is elevated at birth and 2) it decreases rapidly to reach stable levels within 3 wk. Interestingly enough, the plasma creatinine is significantly higher in VLBW infants and appears to be inversely related to GA. The same trend was reported, without comment, by Rudd et al. (25). The neonate's plasma creatinine at birth has been claimed to reflect the mother's plasma concentration (26). This hypothesis does not fit in well, however, with the observation that the plasma creatinine concentration is highest in the most premature infants. If the mother's and the infant's plasma creatinine concentrations were equilibrating through a freely permeable placenta, the premature neonates should have had lower concentrations. The maternal plasma creatinine is indeed lowest at the beginning of the last trimester (27). This corresponds to the peak elevation of GFR during the course of pregnancy (28). The elevated levels of plasma creatinine in the VLBW infants probably reflect the difficulty these infants have eliminating the excess creatinine transferred from the mother: their GFR is still too low during the first postnatal days to effectively eliminate this excess. Also, it cannot be excluded that the level of noncreatinine chromogens increases in the mother during pregnancy and is highest around the 26th

Table 3. Blood pressure $(\mathrm{mm} \mathrm{Hg})$ during the first weeks of life*

\begin{tabular}{|c|c|c|c|c|c|c|}
\hline \multirow[b]{3}{*}{ Group } & \multicolumn{6}{|c|}{ Postnatal days } \\
\hline & \multicolumn{2}{|c|}{$1-2$} & \multicolumn{2}{|c|}{$8-9$} & \multicolumn{2}{|c|}{$15-16$} \\
\hline & Systolic & Diastolic & Systolic & Diastolic & Systolic & Diastolic \\
\hline I $(1001-1500 \mathrm{~g})$ & \multicolumn{2}{|c|}{$n=11$} & \multicolumn{2}{|c|}{$n=10$} & $57 \pm 4$ & $30 \pm 5$ \\
\hline II (1501-2000 g) & \multicolumn{2}{|c|}{$n=15$} & \multicolumn{2}{|c|}{$n=11$} & \multicolumn{2}{|c|}{$n=11$} \\
\hline III $(2001-2500 \mathrm{~g})$ & \multicolumn{2}{|c|}{$n=12$} & \multicolumn{2}{|c|}{$n=7$} & \multicolumn{2}{|c|}{$n=4$} \\
\hline IV (full term) & $63 \pm 2$ & $32 \pm 2$ & $73 \pm 4$ & $41 \pm 6$ & $80 \pm 4$ & $53 \pm 4$ \\
\hline
\end{tabular}

\footnotetext{
${ }^{*}$ Mean values \pm SEM
} 
to 35 th wk of gestation. Finally, the possibility that creatinine back-diffuses across the immature tubular cells, resulting in net reabsorption, must be considered. If such a reabsorption, as is present in immature animals (29), is present in VLBW infants, it could account for the elevated levels of plasma creatinine at birth and also for the slow decrease in levels of plasma creatinine in the most premature infants.

The present results confirm the claim that plasma creatinine concentration should be interpreted with caution during the first postnatal weeks of neonates. During this period, sequential determinations rather than single values of plasma creatinine must be obtained to give valuable information on GFR.

Creatinine clearance. Creatinine clearance was low at birth, the lowest values being observed in the most premature infants. This observation confirms data obtained from creatinine clearance studies $(1,2,8-11)$ or, in a more accurate way, from inulin clearance studies $(3,4,6$, 7). Although inulin remains the best glomerular marker, its measurement is not easy. Consequently, GFR has often been assessed by the clearance of creatinine, which has been shown to correlate reasonably well with inulin clearance. A correlation coefficient of 0.738 was observed by Stonestreet and Oh (30) when the value of creatinine clearance was assessed in VLBW infants and compared with inulin clearance. The scatter of individual values was, however, substantial. Various factors could account for the variability of creatinine clearance in the VLBW infants, related either to 1 ) technical difficulties in the measurement of plasma creatinine in neonates 2) unsteady values of plasma creatinine occurring during the first weeks of life $(8,23,25,30)$, or 3$)$ the possible tubular net reabsorption by back-diffusion of creatinine during the neonatal period. Experimental evidence in piglets (29) and newborn rabbits (unpublished observations) indeed suggests that creatinine is not only filtered but also significantly reabsorbed by the immature kidney. Whether the same characteristics apply to immature infants is not known. These observations, however, clearly point to a possible drawback in the use of creatinine as a glomerular marker in VLBW infants.

With these limitations in mind, creatinine clearance can still be used as an index of GFR. In the present study, the maturation of creatinine followed a characteristic pattern similar to that observed by Svenningsen (14) and Fawer et al. (4) in their studies on the maturation of inulin clearance in newborn infants. Immediately after birth, a progressive increase in creatinine clearance was observed in all infants. This is in contrast with Arant's claim (2) that creatinine clearance does not rise postnatally until the 34th conceptional wk is attained. Although creatinine clearance increased in all groups in the first $3 \mathrm{wk}$ of life, the velocity was significantly different among newborn infants. The slope of maturation was steeper in the most mature infants. This is in agreement with the findings of Aperia et al. (1) but is in contrast with Svenningsen's studies (14) as well as our own previous study
(4). It should be noted that the two latter studies were based on inulin clearance, whereas the former was based on creatinine clearance. Whether the drawbacks associated with creatinine, as described above, account for the discrepancy remains to be demonstrated.

In our studies, creatinine clearance correlated well with mean blood pressure. This is in agreement with our previous finding (4) and has also been observed by others in experimental studies in animals (31). The increase in systemic blood pressure that occurs during postnatal maturation could well result in an increase in glomerular flow and transglomerular pressure in premature neonates whose renal autoregulation may still not be totally efficient.

The present results confirm the concept that birth is a potent stimulus to the development of GFR. From a clinical point of view, the rapid maturation of GFR indicates that the filtration rate must be kept in mind when prescribing drugs or fluids. To avoid the accumulation of drugs excreted mainly by glomerular filtration (aminoglucosides, digoxin, vancomycin), drug dosage has to be adapted to the anticipated level of GFR. When necessary, creatinine clearance is a clinical useful measurement.

Sodium handling. It has been claimed that premature neonates have difficulties in maintaining sodium balance on a standard sodium intake of $1-2 \mathrm{mmol} / \mathrm{kg} / \mathrm{d}$. This phenomenon has been ascribed to urinary losses of sodium by very premature neonates and to a lesser extent to poor intestinal absorption of sodium (32). These losses decrease with increasing gestational and postnatal age. Inability of the preterm kidney to retain sodium has been attributed to deficient proximal reabsorption and to the incapacity of the distal tubule to cope with the delivery of an increased fractional load of sodium despite high serum aldosterone levels (33). In tiny premature infants, fractional sodium excretion has been shown to attain 5 to $15 \%$. Larger preterm infants have somewhat lower fractional excretion rates, amounting to $1-5 \%$ (18).

Our results clearly show that term neonates are able to maintain sodium balance when administered $1-2 \mathrm{mmol} /$ $\mathrm{kg} / \mathrm{d}$ of sodium during the first weeks of life. In preterm neonates, the fractional excretion of sodium that we recorded was not higher than $2.2 \%$, demonstrating that these infants were already able to maintain sodium balance when given sodium intakes of $1-2 \mathrm{mmol} / \mathrm{kg} / \mathrm{d}$. Only in the group of neonates with BW below $1500 \mathrm{~g}$ did the sodium plasma concentration transiently decrease during the second postnatal week. Our findings suggest that the high fractional excretion rates reported previously (15) are not due to tubular immaturity but most probably are iatrogenic in nature. Administering quantities of fluid or sodium that are too large could result in high fractional excretion rates.

The present data confirm those of Shaffer et al. (34) and indicate that sodium balance can be well maintained even in the most premature infants (16) provided that a minimum of $1-2 \mathrm{mmol} / \mathrm{kg} / \mathrm{d}$ of sodium is given for the first $2-3$ 
wk of life. This corresponds to the time when the premature infant must get rid of a large volume of extracellular fluid. After the third week of life, when the excess extracellular fluid has been excreted, sodium intake must be increased to provide enough salt for growth. Sodium intakes of $2-3 \mathrm{mmol} / \mathrm{kg} / \mathrm{d}$ may then be needed.

Our finding that sodium balance is well maintained in premature infants given relatively low sodium intakes of $1-2 \mathrm{mmol} / \mathrm{kg} / \mathrm{d}$ is important. Indeed, the wrong concept that premature babies are always salt losers has led to the inappropriate prescription of large amounts of salt supplements, sometimes reaching $5 \mathrm{mmol} / \mathrm{kg} / \mathrm{d}$. Inappropriate expansion of extracellular volume by elevated intakes of salt and water in premature babies may have severe consequences that include a patent ductus arteriosus, cardiac failure, necrotizing enterocolitis, intracranial hemorrhage, and bronchopulmonary dysplasia (35).

Acknowledgments. The authors thank Professor Calame and the staff of the neonatal unit for their support, as well as C. Heumann, O. Grigoras, and M. Thonney for their valuable help.

\section{REFERENCES}

1. Aperia A, Broberger O, Elinder G, Herin P, Zetterström R 1981 Postnata development of renal function in preterm and full-term infants. Acta Paediatr Scand 70:183-187

2. Arant Jr BS 1978 Developmental patterns of renal functional maturation compared in the human neonate. J Pediatr 92:705-712

3. Guignard JP, Torrado A, Da Cunha O, Gautier E 1975 Glomerular filtration rate in the first three weeks of life. J Pediatr 87:268-272

4. Fawer CL, Torrado A, Guignard JP 1979 Maturation of renal function in full-term and premature neonates. Helv Paediatr Acta 34:11-21

5. Guignard JP 1982 Renal function in the newborn infant. Pediatr Clin North Am 29:777-790

6. Coulthard MG 1983 Comparison of methods of measuring renal function in preterm babies using inulin. J Pediatr 102:923-930

7. van der Heijden AJ, Grose WFA, Ambagtsheer JJ, Provoost AP, Wolff ED, Sauer PJJ 1988 Glomerular filtration rate in the preterm infant: the relation to gestational and postnatal age. Eur J Pediatr 148:24-28

8. Sertel H, Scopes J 1973 Rates of creatinine clearance in babies less than one week of age. Arch Dis Child 48:717-720

9. Siegel SR, Oh W 1976 Renal function as a marker of human fetal maturation. Acta Paediatr Scand 65:481-485

10. Vanpeé M, Herin P, Zetterström R, Aperia A 1988 Postnatal development of renal function in very low birthweight infants. Acta Paediatr Scand 77:191-197
11. Stonestreet BS, Bell EF, Oh W 1979 Validity of endogenous creatinine clearance in low birthweight infants. Pediatr Res 13:1012-1014

12. Ross B, Cowett RM, Oh W 1977 Renal functions of low birth weight infants during the first two months of life. Pediatr Res 11:1162-1164

13. Schulz DM, Giodano DA, Schulz DH 1962 Weights of organ of fetuses and infants. Arch Pathol 74:244-250

14. Svenningsen NW 1975 Single injection polyfructosan clearance in normal and asphyxiated neonates. Acta Paediatr Scand 64:87-95

15. Engelke SC, Shah BL, Vasan U, Raye JR 1978 Sodium balance in very low-birth-weight infants. J Pediatr 93:837-841

16. Sulyok E, Varga F, Györy E, Jobst K, Csaba IF 1979 Postnatal development of renal sodium handling in premature infants. J Pediatr 95:787-792

17. Shaffer SG, Meade VM 1989 Sodium balance and extracellular volume regulation in very low birth weight infants. J Pediatr 115:285-290

18. Aperia A, Broberger O, Herin P, Zetterström R 1979 Sodium excretion in relation to sodium intake and aldosterone excretion in newborn pre-term and full-term infants. Acta Paediatr Scand 68:813-817

19. Dubowitz LMS, Dubowitz V, Goldberg C 1970 Clinical assessment of gestational age in the newborn infant. J Pediatr 77:1-10

20. Du Bois D, Du Bois ES 1916 Clinical calorimetry. X. Formula to estimate the approximate surface area if height and weight be known. Arch Intern Med $17: 863-871$

21. Snedecor GW 1957 Statistical methods applied to experiments in agriculture and biology. Iowa State University Press, Ames

22. Torrado A, Guignard JP, Prod'hom LS, Gautier E 1974 Hypoxaemia and renal function in newborns with respiratory distress syndrome (RDS). Helv Paediatr Acta 29:399-405

23. Siegel SR, Fisher DA, Oh W 1973 Renal function and serum aldosterone levels in infants with respiratory distress syndrome. J Pediatr 83:854-858

24. Feldman H, Guignard JP 1982 Plasma creatinine in the first month of life. Arch Dis Child 57:123-126

25. Rudd PT, Hughes EA, Placzek MM, Hodes DT 1983 Reference ranges for plasma creatinine during the first month of life. Arch Dis Child 58:212-215

26. Manzke H, Spreter von Kreudenstein P, Dörner K, Kruse K 1980 Quantitative measurements of the urinary excretion of creatinine, uric acid, hypoxanthine and xanthine, uracil, cyclic AMP, and cyclic GMP in healthy newborn infants. Eur J Pediatr 133:157-161

27. Davison JM, Dunlop W, Ezimokhai M 198024 hour creatinine clearance during the third trimester of normal pregnancy. Br J Obstet Gynaecol 87:106109

28. Davison JM, Dunlop W 1980 Renal hemodynamics and tubular function in normal human pregnancy. Kidney Int 18:152-161

29. Alt JM, Colenbrander B, Forsling ML, Macdonald AA 1984 Perinatal development of tubular function in the pig. Q J Exp Physiol 69:693-702

30. Stonestreet BS, Oh W 1978 Plasma creatinine levels in low-birth-weight infants during the first three months of life. Pediatrics 61:788-789

31. Gruskin AB, Edelmann CM, Yuan S 1970 Maturational changes in renal blood flow in piglets. Pediatr Res 4:7-13

32. Al-Dahhan J, Haycock GB, Chantler C, Stimmler L 1983 Sodium homeostasis in term and preterm neonates. Arch Dis Child 58:343-345

33. Sulyok E, Németh M, Tényi I, Csaba I, Györy E, Ertl T, Varga F 1979 Postnatal development of renin-angiotensin-aldosterone system, RAAS, in relation to electrolyte balance in premature infants. Pediatr Res 13:817-820

34. Shaffer SG, Bradt SK, Meade VM, Hall RT 1987 Extracellular fluid volume changes in very low birth weight infants during first 2 postnatal months. $J$ Pediatr 11:124-128

35. Guignard JP, John EG 1986 Renal function in the tiny, premature infant. Clin Perinatol 13:377-401 